\title{
PERAN KEPUASAN PELANGGAN MEMEDIASI KUALITAS LAYANAN TERHADAP LOYALITAS PELANGGAN PADA PT. AIRASIA INDONESIA
}

\author{
Anak Agung Ayu Ratna Maheswari \\ Ni Made Asti Aksari \\ Fakultas Ekonomi dan Bisnis Universitas Udayana (Unud), Bali, Indonesia \\ e-mail: ratnamaheswari98@yahoo.com
}

\begin{abstract}
ABSTRAK
Banyaknya aktivitas masyarakat yang menggunakan jasa penerbangan menuntut maskapai penerbangan untuk dapat memberikan kualitas layanan yang baik sehingga konsumen menjadi puas dan loyal. Tujuan dari penelitian ini adalah untuk menjelaskan pengaruh kualitas layanan terhadap kepuasan dan loyalitas pelanggan, pengaruh kepuasan pelanggan terhadap loyalitas pelanggan, serta untuk menjelaskan peran kepuasan pelanggan dalam memediasi hubungan antara kualitas layanan dan loyalitas pelanggan pada jasa penerbangan AirAsia. Penelitian ini menggunakan sampel sebanyak 130 pelanggan AirAsia yang berada di Bandara Internasional Ngurah Rai dan Kota Denpasar, dimana sampel ditentukan dengan metode purposive sampling. Data dikumpulkan dengan menyebarkan kuisioner dengan skala likert lima poin untuk mengukur 13 indikator, dan teknik analisis yang digunakan adalah analisis path. Hasil penelitian menunjukkan bahwa kualitas layanan berpengaruh positif terhadap kepuasan dan loyalitas pelanggan AirAsia, kepuasan pelanggan berpengaruh positif terhadap loyalitas pelanggan AirAsia, dan mampu memediasi pengaruh kualitas layanan terhadap loyalitas pelanggan AirAsia. Saran yang dapat diberikan kepada perusahaan penerbangan AirAsia adalah untuk memperhatikan kualitas layanannya dengan meningkatkan ketepatan waktu keberangkatan pesawat sehingga pelanggan merasa puas dan menjadi pengguna loyal AirAsia.
\end{abstract}

Kata kunci: kualitas layanan, kepuasan pelanggan, loyalitas pelanggan.

\begin{abstract}
The amount of activities that requires airline services demands airline companies to provide good quality services to create satisfied and loyal consumers. The purpose of this study is to explain the effect of service quality on customer satisfaction and customer loyalty, the effect of customer satisfaction on customer loyalty, and to explain the mediating role of customer satisfaction in the effect of service quality on customer loyalty of AirAsia airline. Through purposive sampling method, this study uses a sample of 130 AirAsia customers at Ngurah Rai International Airport and Denpasar City, data was collected using questionnaire with a five-point Likert scale to measure 13 indicators, and analysed using path analysis. The result shows that service quality have a positive effect on customer satisfaction and their loyalty on AirAsia airline, customer satisfaction have a positive effect on customer loyalty on AirAsia airline, and customer satisfaction mediates the effect of service quality towards customer loyalty on AirAsia airline. We recommend for AirAsia to pay close attention to the quality of its services by controlling its flight schedule punctuality to satisfy its customers, which in turn will become loyal customers of AirAsia airline.
\end{abstract}

Keywords: Service Quality, Customer Satisfaction, Customer Loyalty. 
Anak Agung Ayu Ratna Maheswari dan Ni Made Asti Aksari, Peran Kepuasan Pelanggan...

\section{PENDAHULUAN}

Transportasi udara merupakan salah satu transportasi yang memiliki efisiensi, kecepatan, dan kenyamanan yang baik bagi masyarakat. Jenis transportasi yang dapat menghubungkan antara satu wilayah ke wilayah lainnya, satu pulau kepulau lainnya adalah transportasi udara atau pesawat udara. Menurut (Nissalke, 2009) transportasi udara merupakan salah satu komponen terpenting dalam sistem tranportasi dunia, bukan hanya menyediakan sarana utama perjalanan jarak jauh di dunia, tetapi memiliki dampak ekonomi terhadap perekonomian global dan nasional. Peranan dan perkembangan pada sektor jasa khusunya transportasi udara di Indonesia terasa semakin penting, karena banyak aktivitas masyarakat yang menggunakan jasa transportasi udara.

Pengguna jasa penerbangan di Indonesia saat ini mencapai 60 juta orang dan akan semakin bertambah di masa mendatang. Sehingga, pada jaman globalisasi ini jumlah maskapai penerbangan semakin banyak dan rute penerbangan semakin bertambah (Triwijanarko, 2018). Semakin berkembangnya penerbangan di Indonesia dengan munculnya tren penerbangan yang murah atau lebih dikenal dengan low cost carrier atau juga dikenal low cost airlines membuat masyarakat lebih memilih menggunakan jasa penerbangan dibandingkan jasa transportasi lainnya, karena dianggap lebih efisien dalam waktu. Low cost carrier salah satu penerbangan dengan mengupayakan harga seefisien mungkin, jika dibandingkan

dengan harga pada penerbangan regular melalui pengurangan berbagai fasilitas seperti yang di dapatkan pada penerbangan full service seperti majalah, in-flight entertainment, in-flight shop, lounge, free taxy after landing, exclusive frequent 
flier services dan lain sebagainya (Sandy, 2016). Penerbangan jenis ini mampu menawarkan biaya yang rendah dengan mengurangi beberapa layanan umum bagi penumpang pesawat seperti layanan catering, dan meminimalisasi reservasi sehingga berakibat pada penurunan biaya. Perkembangan low cost carrier di Indonesia membuat persaingan dalam bisnis terus meningkat, dimana penerbangan dengan biaya rendah mampu menarik minat masyarakat untuk menggunakan transportasi udara yaitu pesawat. Penerbangan di Indonesia yang menerapkan low cost carrier yaitu, Lion Air, AirAsia, Citilink, dan Sriwijaya Air.

AirAsia merupakan salah satu maskapai penerbangan asing yang beroperasi di Indonesia. Maskapai yang sebelumnya bernama AWAIR (Air Wagon Internasional) ini memfokuskan pada biaya penerbangan yang rendah namun berkualitas. Pada tahun 2004, AirAsia mengakuisisi AWAIR dan mengubah namanya menjadi AirAsia Indonesia. Setelah berubah nama, AirAsia Indonesia dengan strategi biaya murah. Tanggal 8 Desember 2004 Air Asia Indonesia diluncurkan kembali dalam meramaikan dunia penerbangan Indonesia sebagai maskapai penerbangan berbiaya rendah dan mengusung konsep yang sama dengan Group AirAsia Indonesia (Surbakti, 2013).

Untuk memenuhi antusias masyarakat Indonesia terhadap hadirnya maskapai low cost carrier yang aman dan nyaman serta mewujudkan impian semua orang agar dapat terbang dengan pesawat, AirAsia melakukan pengembangan serta penambahan armada, diikuti dengan penerapan tarif berbiaya terjangkau oleh AirAsia. Penerbangan dengan biaya terjangkau merupakan suatu solusi inovatif yang dikembangkan AirAsia untuk mendukung level penerbangan berbiaya rendah 
Anak Agung Ayu Ratna Maheswari dan Ni Made Asti Aksari, Peran Kepuasan Pelanggan...

namun berkualitas. AirAsia memiliki slogan yang berbunyi "Sekarang Siapapun Bisa Terbang (Now Everyone Can Fly)" (Airasia, 2012). Konsep low cost carrier yang diterapkan pada AirAsia mendapatkan beberapa kesan buruk yang terjadi pada AirAsia, antara lain yaitu keluhan konsumen tentang kualitas layanan yang diberikan oleh AirAsia.

Kualitas layanan merupakan upaya perusahaan dalam memenuhi harapan pelanggan melalui produk atau jasa yang ditawarkan dengan tujuan untuk menciptakan kepuasan pelanggan. Menurut (Artha, 2019) Kualitas layanan memiliki peranan penting atas keberhasilan dalam memberikan jaminan kepuasan bagi konsumen. Pelanggan menilai kualitas layanan suatu perusahaan setelah mereka menerima dan merasakan layanan tersebut. Hal ini dapat membuktikan layanan yang bermutu ditunjukan oleh kesesuaian layanan yang diterima dengan yang diharapkan akan menciptakan kepuasan pelanggan. (Mardikawati \& Farida, 2013) menyatakan kualitas pelayanan ada berpengaruh positif dan signifikan terhadap kepuasan konsumen. (Sudjarwo, 2015) menemukan kualitas pelayanan berpengaruh positif terhadap kepuasan nasabah. Menurut (Afifah, 2014) kualitas pelayanan adalah tingkat keunggulan jasa yang diharapkan dan pengendalian tingkat keunggulan tersebut untuk memenuhi keinginan konsumen. Konsumen yang puas dengan pelayanan yang diberikan dapat mempengaruhi kehidupan perusahaan dan meningkatkan profit perusahaan.

Kepuasan pelanggan merupakan faktor yang sangat menentukan dalam pemas aran, sebaliknya kekecewaan pelanggan saat mendapat layanan bisa menjadikan kehancuran perusahaan di masa mendatang. Dalam pasar yang tingkat persaingan 
cukup tinggi, kepuasaan pelanggan dan loyalitas pelanggan saling berhubungan yang artinya bila ada usaha dari perusahaan untuk mengikat kepuasan pada pelanggan maka loyalitas pelanggan juga akan meningkat begitu pula sebaliknya bila perusahaan menurunkan kepuasan pada pelanggan maka secara tidak langsung loyalitas pelanggan juga akan menurun. Jadi dalam hal ini kepusaan pelanggan dapat menyebabkan peningkatan atau penurunan pada loyalitas pelanggan. Penyataan tersebut relevan dengan penelitian lain yang dilakukan (Hafeez, 2012); (Sabir, 2013); (Sauqi, 2015); (Wijayanto, 2015); (Fikri, 2016); (Minh, 2016) dan (Pamungkas, 2016) yang menyatakan bahwa kepuasan pelanggan mempunyai pengaruh positif dan signifikan terhadap loyalitas pelanggan.

Loyalitas pelanggan terhadap suatu produk merupakan kunci sukses dalam sebuah perusahaan. Konsumen yang merasa puas terhadap suatu produk atau jasa biasanya akan menciptakan loyalitas pelanggan. Loyalitas pelanggan memiliki peran pentinng dalam perusahaan, dimana mempertahankan loyalitas pelanggan berarti meningkatkan kualitas perusahaan dan mempertahankan kelangsungan hidup perusahaan. Tingginya tingkat penjualan mengindikasikan tingginya loyalitas pelanggan yang dimiliki konsumen, kepuasan yang dimiliki pelanggan digunakan sebagai pemediasi kualitas produk dan kualitas layanan terhadap loyalitas pelanggan. Menurut (Afifah, 2014) loyalitas pelanggan merupakan suatu ukuran yang dapat dilakukan untuk mempredisikan pertumbuhan penjualan dan keuangan. Konsumen yang loyal biasanya akan merekomendasikan produk dan jasa yang digunakan kepada orang-orang terdekat, selain itu pelanggan yang sudah 
Anak Agung Ayu Ratna Maheswari dan Ni Made Asti Aksari, Peran Kepuasan Pelanggan...

cocok dengan layanan dan produk yang ditawarkan jarang untuk berpindah tempat atau merek.

AirAsia berhasil mempertahankan low cost carrier dengan tetap memberi tarif yang terjangkau bagi semua kalangan. Sejak saat itu, persaingan di industri penerbangan tanah air semakin pesat. Maskapai lain mulai mengikuti sistem low cost carrier dan perkembangan low cost carrier ini diperkirakan naik hingga 7 persen setiap tahunnya. Dalam hal ini AirAsia banyak memiliki pesaing yang menggunakan low cost carrier dan membuat menurunya market share di Indonesia pada maskapai AirAsia.

Tabel 1

Market Share Rute Penerbangan Maskapai Air Asia Indonesia

\begin{tabular}{lccccc}
\hline & 2013 & 2014 & 2015 & 2016 & 2017 \\
\hline Internasional & $26 \%$ & $27 \%$ & $27 \%$ & $27 \%$ & $18,3 \%$ \\
Domestik & $5 \%$ & $5 \%$ & $3 \%$ & $2 \%$ & $1,2 \%$ \\
\hline Total & $\mathbf{1 0 \%}$ & $\mathbf{1 1 \%}$ & $\mathbf{9 \%}$ & $\mathbf{8 \%}$ & $\mathbf{5 , 9 \%}$ \\
\hline
\end{tabular}

Sumber: Annual Report Air Asia 2013-2017

Pada Tabel 1 menunjukan market share AirAsia dalam rute Internasional lebih dominan dibandingkan rute penerbangan Domestik, dimana pada tahun 2013 hingga tahun 2014 rute penerbangan Internasional meningkat 1 persen dan ditahun 2014 hingga tahun 2016 rute penerbangan internasional tetap dengan persentase 27 persen. Sedangkan pada tahun 2017 rute penerbangan Internasional mengalami penurunan hingga 8,7 persen. Rute penerbangan Domestik pada tahun 2014 hingga tahun 2017 terus mengalami penurunan, dimana persentase pada tahun 2017 mengalami penurunan menjadi 1,2 persen dari tahun 2016 dengan persentase 2 persen. 
Adanya penurunan pada market share Air Asia di Indonesia ini menyatakan adanya masalah dalam maskapai penerbangan tersebut. Tahun 2017 AirAsia mengalami penurunan jumlah penumpang hingga 4 persen dibandingkan tahun sebelumnya, dikarenakan permintaan yang melemah. Sepanjang 6 bulan terakhir, tingkat ketepatan waktu terbang atau OTP (On Time Performance) masakapi juga belum memuaskan (Tempo, 2009). Posisi AirAsia dalam kategori transportasi penerbangan menunjukan penurunan presentase dan posisi secara perlahan-lahan, posisi yang dicapai AirAsia selama ini harus digantikan oleh maskapai penerbangan Low Cost Carrier lain disebabkan adanya persaingan dari penerbangan Low Cost Carrier yang dimana mampu memberikan pelayanan yang lebih baik dari AirAsia, sehingga pelanggan yang biasanya menggunakan pelayanan AirAsia beralih ke maskapai penerbangan Low Cost Carrier lainnya. AirAsia secara Internasional mampu mempertahankan World's Best Low-Cost Airlanes dari SKAYTRAX namun tidak di Indonesia, yang mana tidak terlalu mempengaruhi presepsi konsumen Indonesia, hal ini banyak pelanggan yang kurang puas terhadap kualitas pelayanan yang diberikan AirAsia Indonesia yang menyebabkan menurunnya persentase market share di Indonesia.

Berdasarkan uraian latar belakang dan penelitian sebelumnya, menunjukkan adanya peran kepuasan pelanggan dalam memediasi kualitas layanan terhadap loyalitas pelanggan pada PT. Air Asia Indonesia. Penelitian ini dilakukan pada PT. Air Asia Indonesia karena adanya masalah kualitas pelayanan pada maskapai AirAsia. 
Penelitian (Adil, 2013) menunjukan tingkat kualitas layanan yang tinggi dirasakan pada lima dimensi kualitas layanan sedangkan hasil analisis regresi menunjukan bahwa adanya kendala dan jaminan yang berpengaruh terhadap kepuasan pelanggan secara keseluruan. (Lee, 2013) dalam penelitiannya juga menunjukan kualitas layanan juga berpengaruh positif terhadap kepuasan pelanggan. Menurut (Maimunah \& Djawoto, 2017), hasil pengujian menunjukan kualitas pelayanan berpengaruh signifikan terhadap kepuasan pelanggan.

Berdasarkan uraian diatas, maka dapat dibuat hipotesis yang diajukan adalah sebagai berikut:

$\mathrm{H}_{1} \quad$ : Kualitas layanan berpengaruh positif dan signifikan terhadap kepuasan pelanggan.

Menurut penelitian yang telah dilakukan (Lee, 2013) menunjukan hasil bahwa kualitas layanan perusahaan berpengaruh positif dan signifikan terhadap loyalitas pelanggan. Penelitian yang dilakukan oleh (Mardikawati \& Farida, 2013) yang menyatakan bahwa kualitas layanan berpengaruh secara positif terhadap loyalitas pelanggan melalui kepuasan pelanggan. (Permana \& Nurcahya, 2014) menyatakan bahwa kualitas layanan berpengaruh positif dan signifikan terhadap loyalitas pelanggan. Berdasarkan uraian diatas, maka dapat dibuat hipotesis yang diajukan sebagai berikut:

$\mathrm{H}_{2} \quad$ : Kualitas Layanan berpengaruh positif dan signifikan terhadap loyalitas pelanggan 
(Jahanshahi, 2011) menyatakan bahwa kepuasan pelanggan berpengaruh terhadap loyalitas pelanggan. (Asgharian, 2012) menyatakan bahwa kepuasan pelanggan ada pengaruh positif dan signifikan anatara kepuasan pelanggan terhadap loyalitas pelanggan. (Lee, 2013) menunjukan hasil bahwa kepuasan pelanggan memiliki pengaruh positif dan signifikan terhadap loyalitas. (Raharjo, 2013) dalam penelitiannya menyatakan bahwa kepuasan berpengaruh positif terhadap loyalitas pelanggan. (Sandada \& Matibiri, 2015) dalam penelitiannya menunjukan kepuasan pelanggan berpengaruh signifikan terhadap loyalitas pelanggan. Berdasarkan uraian diatas, maka dapat dibuat hipotesis yang diajukan adalah sebagai berikut:

$\mathrm{H}_{3}$ : Kepuasan pelanggan berpengaruh positif dan signifikan terhadap loyalitas pelanggan.

Penelitian yang dilakukan oleh (Starini, 2013) menemukan bahwa pengaruh kualitas pelayanan terhadap loyalitas konsumen dengan kepuasan sebagai variabel mediasi mempunyai pengaruh yang positif dan juga signifikan. Penelitian dari (Malik, 2012) juga menunjukan hasil yang sama yaitu kepuasan pelanggan berpengaruh positif dan signifikan dalam memediasi pengaruh kualitas layanan dengan loyalitas pelanggan. (Aditya \& Kusumadewi, 2017) juga menemukan adanya pengaruh positif dan signifikan antara kualitas layanan terhadap loyalitas pelanggan yang dimediasi oleh kepuasan pelanggan. Penelitian yang dilakukan (Irnandha, 2017) kualitas layanan tidak berpengaruh terhadap loyalitas pelanggan yang dimediasi kepuasan pelanggan. Berdasarkan uraian diatas, maka dapat dibuat hipotesis yang diajukan adalah sebagai berikut: 
Anak Agung Ayu Ratna Maheswari dan Ni Made Asti Aksari, Peran Kepuasan Pelanggan...

$\mathrm{H}_{4}$ : Kepuasan pelanggan berpengaruh positif dan signifikan dalam memediasi kualitas layanan terhadap loyalitas pelanggan.

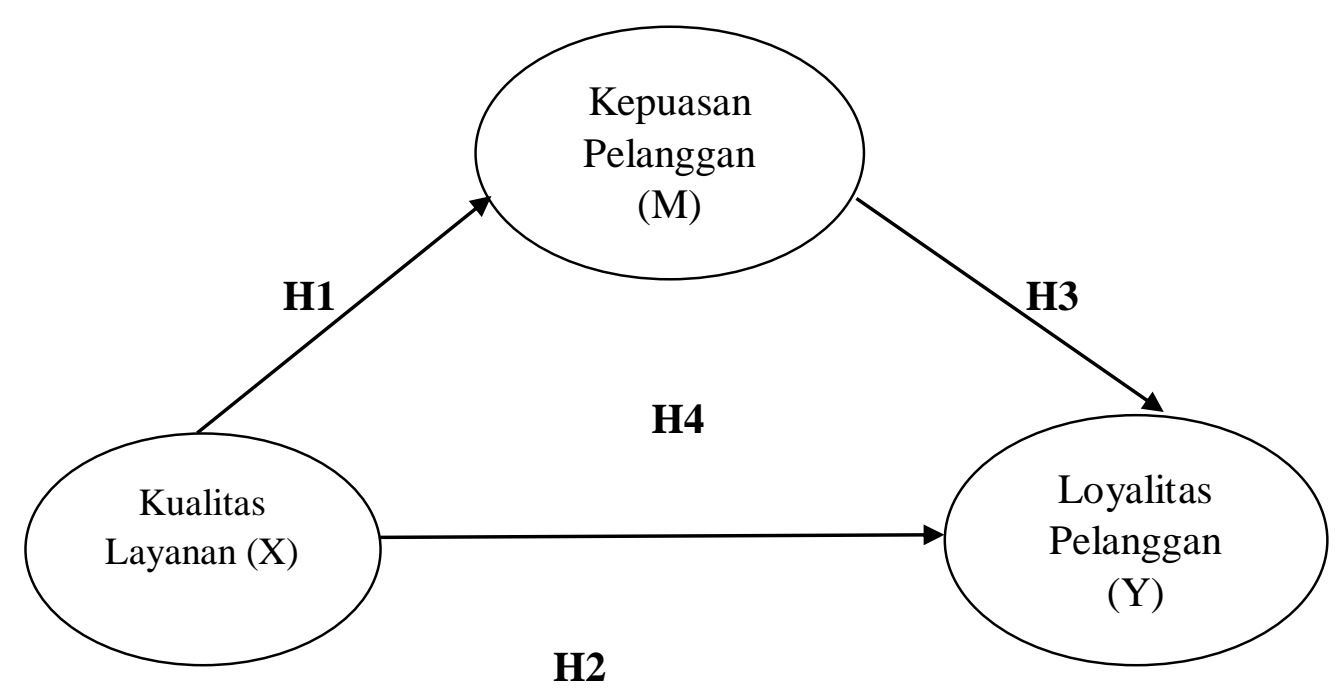

Gambar 1. Kerangka Konsetual Peran Kepuasan Pelanggan Dalam Memediasi Kualitas Layanan Terhadap Loyalitas Pelanggan Pada PT. AirAsia Indonesia.

Sumber: Data Primer Diolah, 2018.

\section{METODE PENELITIAN}

Lokasi penelitian ini dilakukan di Bandara Internasional Ngurah Rai, yang terletak di Daerah Badung, selain itu lokasi penelitian ini juga dilakukan di Kota Denpasar. Dipilihnya Daerah Badung dan Kota Denpasar karena rata-rata pendapatan penduduk di Daerah Badung dan Kota Denpasar pada tahun 2017 berada di peringkat pertama dan kedua dari seluruh wilayah Provinsi Bali (BPS, 2018). Oleh karena itu, penduduk Daerah Badung dan Kota Denpasar memiliki peluang tinggi untuk menggunakan jasa maskapai penerbangan AirAsia. Variabel bebas adalah variabel yang menjadi sebab timbulnya atau berubah variabel terikat. 
Dalam penelitian ini yang merupakan variabel bebas adalah kualitas layanan yang disimbolkan dengan $(\mathrm{X})$.

Penelitian ini dilakukan dengan menggunakan kuisioner yang disebarkan secara tidak langsung kepada responden dan dijawab sendiri oleh responden, penyebaran kuisioner dilakukan dengan menyebarkan link pada web Google Docs. Ruang lingkup pada penelitian ini hanya di wilayah Kota Denpasar dan Daerah Badung, sehingga hasil penelitian ini belum tentu akan sama dengan responden yang berada diluar wilayah Denpasar dan Daerah Badung Penelitian ini juga hanya dilakukan dalam jangka waktu tertentu (cross section), sedangkan lingkungan dapat berubah setiap saat (dinamis), sehingga penelitian ini perlu dikembangkan dimasa mendatang. Penelitian ini masih bisa dikembangkan dengan merubah subjek dari penelitian ini, karena penelitian ini akan memberikan hasil yang mungkin berbeda ketika produk yang digunakan sebagai bahan penelitian diubah.

Variabel mediasi adalah variabel yang menjembatani antara variabel bebas dan terikat. Dalam penelitian ini yang merupakan variabel mediasi adalah kepuasan pelanggan yang disimbolkan dengan (M). Variabel terikat adalah variabel yang dipengaruhi atau yang menjadi akibat karena adanya variabel bebas. Variabel terikat dalam penelitian ini adalah loyalitas pelanggan yang disimbolkan dengan (Y).

Populasi dalam penelitian ini seluruh pelanggan yang telah menggunakan produk dan jasa penerbangan AirAsia. Teknik pengambilan sampel yang digunakan dalam penelitian ini adalah non random sampling, dimana tidak semua individu 
dalam populasi diberi kesempatan yang sama untuk ditugaskan menjadi anggota sampel. Teknik non probability sampling yang digunakan dalam penelitian ini adalah purposive sampling, yaitu teknik penentuan sampel dengan pertimbangan atau kriteria tertentu. Kriteria sampel dalam penelitian ini sdalah: berdomisili di Badung dan Denpasar, berusia 17th keatas, dan lebih dari 2 kali dalam setahun terakhir menggunakan jasa penerbangan pesawat AirAsia. Menurut Sugiyono (2013) ukuran sampel terganntung pada jumlah indikator kali 5 sampai 10. Bila terdapat 13 indikator, ukuran sampel adalah antara 65 sampai 130. Jumlah ukuran sampel yang diambil dari penelitian ini adalah sebagai berikut:

$$
\begin{array}{ll}
\text { Jumlah sampel } & =\text { jumlah indikator } \times 10 \\
& =13 \times 10 \\
& =130
\end{array}
$$

Maka, umlah ukuran sampel yang digunakan dalam penelitian ini adalah 130 responden. Teknik analisis data yang digunakan dalam penelitian ini adalah analisis jalur (Path Analysis).

Persamaan Sub-struktural 1

$$
\mathrm{M}=\beta_{2} \mathrm{X}+\mathrm{e}_{1}
$$

Persamaan Sub-struktural 2

\begin{tabular}{|c|c|}
\hline Y & $=$ Loyalitas pelanggan \\
\hline$X$ & $=$ Kualitas layanan \\
\hline M & $=$ Kepuasan pelanggan \\
\hline $\begin{array}{l}\beta_{1}, \beta_{2}, \beta_{3} \\
\mathrm{e}\end{array}$ & $\begin{array}{l}=\text { Koefisien regresi variabel } \\
=\text { Error }\end{array}$ \\
\hline
\end{tabular}

$$
\mathrm{Y}=\beta_{1} \mathrm{X}+\beta_{3} \mathrm{M}+\mathrm{e}_{2}
$$

Keterangan : 
Pengujian hipotesis mediasi dilakukan dengan prosedur yang dikembangkan oleh (Sobel, 1982) dan dikenal dengan Uji Sobel (Sobel Test).Uji Sobel digunakan dengan menguji kekuatan pengaruh tidak langsung variabel kualitas layanan (X) terhadap variabel loyalitas pelanggan (Y) melalui variabel kepuasan pelanggan (M).

\section{HASIL DAN PEMBAHASAN}

Penelitian ini menggunakan 130 orang sebagai responden. Karakteristik responden dapat dilihat pada Tabel 2.

Tabel 2

Karakteristik Responden

\begin{tabular}{|c|c|c|c|c|}
\hline No & Karakteristik & Klasifikasi & $\begin{array}{c}\text { Jumlah } \\
\text { Responden }\end{array}$ & Persentase \\
\hline \multirow[t]{3}{*}{1} & \multirow[t]{2}{*}{ Jenis Kelamin } & Perempuan & 68 & 52,3 \\
\hline & & Laki-laki & 62 & 47,7 \\
\hline & \multicolumn{2}{|c|}{ Jumlah } & 130 & 100 \\
\hline \multirow{4}{*}{2} & \multirow{3}{*}{ Usia } & 17-20 Tahun & 30 & 23,1 \\
\hline & & 21-30 Tahun & 55 & 42,3 \\
\hline & & $>30$ Tahun & 45 & 34,6 \\
\hline & \multicolumn{2}{|c|}{ Jumlah } & 130 & 100 \\
\hline \multirow{5}{*}{3} & \multirow{5}{*}{ Jenis Pekerjaan } & Pelajar/Mahasiswa & 20 & 15,4 \\
\hline & & Pegawai Swasta & 30 & 23,1 \\
\hline & & Pegawai Negeri & 30 & 23,1 \\
\hline & & Wiraswasta & 45 & 34,6 \\
\hline & & Lainnya & 5 & 3,8 \\
\hline & Jumlah & & 130 & 100 \\
\hline
\end{tabular}

Sumber: Data diolah, 2018

Tabel 2 menunjukkan bahwa pada penelitian ini didominasi oleh responden berjenis kelamin perempuan sebanyak 68 responden dengan persentase sebesar 52,3 persen, sedangkan responden berjenis kelamin laki-laki sebanyak 62 orang dengan persentase sebesar 47,7 persen. Untuk kategori usia, mayoritas responden 
berada dalam rentang usia 21-30 tahun yaitu sebanyak 55 orang, diikuti oleh responden berusia diatas 30 tahun sebanyak 45 orang, kemudian responden berusia 17-20 tahun adalah 30 orang. Berdasarkan jenis pekerjaan, mayoritas responden berprofesi sebagai wiraswasta dengan persentase sebesar 34,6 persen, diikuti oleh profesi pegawai negeri dan pegawai swasta masing-masing dengan persentase 23,1 persen, kemudian responden yang merupakan pelajar adalah 15,4 persen, dan terdapat juga responden yang berprofesi lainnya seperti, bidan, perawat, dan desainer dengan presentase terendah yaitu 3,8 persen.

Perhitungan koefisien path dilakukan dengan analisis regresi melalui software SPSS for Windows, diperoleh hasil yang ditunjukan pada Tabel 3 berikut.

\section{Tabel 3}

\section{Hasil Analisis Jalur Persamaan Regresi 1}

\begin{tabular}{lcccc}
\hline \multicolumn{1}{c}{ Variabel } & $\begin{array}{c}\text { Standardized } \\
\text { Coefficients }\end{array}$ & Std. Error & $\begin{array}{c}\mathrm{t} \\
\text { hitung }\end{array}$ & $\begin{array}{c}\text { Sig. uji } \\
\mathrm{t}\end{array}$ \\
\hline (Constant) & & 0,163 & - & 0,821 \\
& & & 0,227 & \\
Kualitas Layanan (X) & 0,897 & 0,044 & 22.981 & 0,000 \\
R Square & 0,805 & & & \\
F Statistik & 528,126 & & & \\
Signifikansi Uji F & 0,000 & & & \\
Sumber: Data diolah, 2018 & & &
\end{tabular}

Berdasarkan hasil analisis jalur substruktur 1 seperti yang dilihat pada tabel 3, maka persamaan strukturalnya adalah sebagai berikut:

$\mathrm{M}=\beta_{1} \mathrm{X}+\mathrm{e}_{1}$

$M=0,897 X+e_{1}$

Nilai $\beta_{1}$ adalah sejumlah 0,897 memiliki kualitas layanan berpengaruh positif terhadap kepuasan pelanggan, hal ini menunjukan bahwa apabila variabel 
kualitas layanan meningkat maka kepuasan pelanggan dari maskapai penerbangan AirAsia akan meningkat sebanyak 0,897.

\section{Tabel 4}

\section{Hasil Analisis Jalur Persamaan Regresi 2}

\begin{tabular}{lcccc}
\hline \multicolumn{1}{c}{ Variabel } & $\begin{array}{c}\text { Standardized } \\
\text { Coefficients }\end{array}$ & Std. Error & $\begin{array}{c}\mathrm{t} \\
\text { hitung }\end{array}$ & $\begin{array}{c}\text { Sig. uji } \\
\mathrm{t}\end{array}$ \\
\hline (Constant) & & 0,261 & - & 0,827 \\
& & & 0,219 & \\
Kualitas Layanan (X) & 0,423 & 0,159 & 3,426 & 0,001 \\
Kepuasan Pelanggan (M) & 0,388 & 0,141 & 3,146 & 0,002 \\
R Square & 0,623 & & & \\
F Statistik & 105,017 & & & \\
Signifikansi Uji F & 0,000 & & & \\
Sumber: Data diolah, 2018 & & & &
\end{tabular}

Berdasarkan hasil analisi jalur substruktural 2 seperti yang dilihat pada tabel 4, maka persamaan strukturalnya adalah sebagai berikut:

$\mathrm{Y}=\beta_{2} \mathrm{X}+\beta_{3} \mathrm{Y} 1+\mathrm{e}_{1}$

$\mathrm{Y}=0,423 \mathrm{X}+0,388 \mathrm{Y} 1+\mathrm{e}_{2}$

Berdasarkan persamaan tersebut maka dapat disimpulkan bahwa nilai $\beta_{2}$ sejumlah 0,423 berarti kualitas layanan berpengaruh positif terhadap loyalitas pelanggan, dengan kata lain jika variabel kualitas layanan meningkat maka variabel loyalitas pelanggan pada maskapai penerbangan AirAsia akan meningkat sebanyak 0,423 .

Nilai $\beta_{3}$ sejumlah 0,388 berarti kepuasan pelanggan berpengaruh positif terhadap loyalitas pelanggan, hal ini berarti apabila variabel kepuasan pelanggan meningkat maka variabel loyalitas pelanggan pada maskapai penerbangan AirAsia meningkat sebanyak 0,388 . 
Berdasarkan model subtruktural 1 dan model suntruktural 2, maka dapat disusun model diagram jalur akhir. Sebelum menyusun model diagram jalur akhir, terlebih dahulu dihitung nilai standar error sebagai berikut:

$$
\begin{aligned}
& \mathrm{Pe}=\sqrt{1-R^{2}} \\
& \mathrm{Pe}_{1}=\sqrt{1-R 1^{2}}=\sqrt{1-0,805}=0,441 \\
& \mathrm{Pe}_{2}=\sqrt{1-R 2^{2}}=\sqrt{1-0,623}=0,614
\end{aligned}
$$

Berdasarkan perhitungan pengaruh error (e), didapatkan hasil pengaruh error $\left(\mathrm{e}_{1}\right)$ sebesar 0,441 dan pengaruh error $\left(\mathrm{e}_{2}\right)$ sebesar 0,614. Hasil koefisien determinasi total adalah sebagai berikut:

$$
\begin{aligned}
\mathrm{R}^{2} \mathrm{~m} & =1-\left(\mathrm{Pe}_{1}\right)^{2}\left(\mathrm{Pe}_{2}\right)^{2} \\
& =1-(0,441)^{2}(0,614)^{2} \\
& =1-(0,194)(0,376) \\
& =1-0,339 \\
& =0,928
\end{aligned}
$$

Nilai determinasi total sebesar 0,928 memiliki arti bahwa 92,8 persen variabel loyalitas dipengaruhi oleh variabel kualitas layanan dan kepuasan pelanggan, sisanya sebesar 7,2 persen dijelaskan oleh faktor lain di luar model yang dibentuk. Hasil koefisien jalur pada hipotesis penelitian dapat digambarkan pada gambar 2 berikut: 


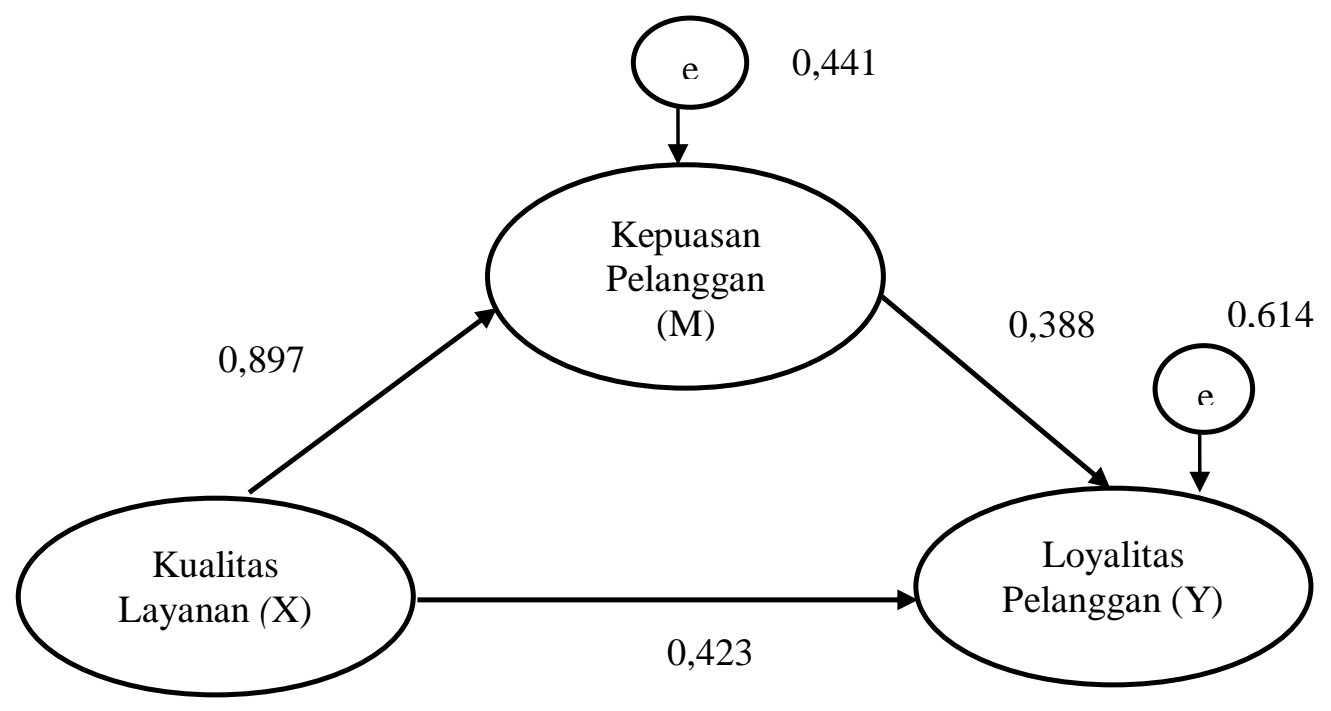

Gambar 2. Diagram Koefisien Jalur X terhadap Y melalui M

Sumber: Data Primer Diolah, 2018.

Tabel 5

Pengaruh Langsung, Pengaruh Tidak Langsung dan Pengaruh Total

\begin{tabular}{|c|c|c|c|}
\hline Pengaruh Variabel & $\begin{array}{l}\text { Pengaruh } \\
\text { Langsung }\end{array}$ & $\begin{array}{c}\text { Pengaruh Tidak } \\
\text { Langsung } \\
(\mathrm{M})=\left(\boldsymbol{\beta}_{1 \times 1} \beta_{2}\right)\end{array}$ & Peran Total \\
\hline $\begin{array}{l}\text { Kualitas L }(\mathrm{X}) \rightarrow \text { Kepuasan } \\
\text { Pelanggan }(\mathrm{M})\end{array}$ & 0,897 & - & 0,897 \\
\hline $\begin{array}{l}\text { Kualitas } \quad \mathrm{L} \quad(\mathrm{X}) \underset{ }{\text { Loyalitas Pelanggan }(\mathrm{Y})} \rightarrow \\
\rightarrow\end{array}$ & 0,423 & 0,348 & 0,771 \\
\hline $\begin{array}{l}\text { Kepuasan Pelanggan (M) } \\
\rightarrow \text { Loyalitas P (Y) }\end{array}$ & 0,388 & - & 0,388 \\
\hline
\end{tabular}

Sumber: (data diolah), 2018.

Analisis direct effect, indirect effect, dan total effect dapat digunakan untuk melihat pengaruh kekuatan antar konstruk, baik yang secara langsung, tidak langsung, maupun pengaruh totalnya. Berdasarkan tabel 5, maka dapat diartikan bahwa variabel kualitas layanan memiliki pengaruh secara langsung terhadap variabel kepuasan pelanggan sebesar 0,897, variabel kualitas layanan mempengaruhi secara langsung terhadap variabel loyalitas pelanggan sebesar 0,423 
Anak Agung Ayu Ratna Maheswari dan Ni Made Asti Aksari, Peran Kepuasan Pelanggan...

dan pengaruh secara tidak langsung sebesar 0,348. Pada variabel kepuasan pelanggan memiliki pengaruh secara langsung terhadap variabel loyalitas pelanggan sebesar 0,388. Variabel kualitas layanan memiliki pengaruh secara langsung terhadap loyalitas pelanggan sebesar 0,423 dan pengaruh tidak langsung sebesar 0,348 , hal ini dapat berarti bahwa pengaruh variabel kualitas layanan dengan loyalitas pelanggan akan meningkat apabila pengaruh tersebut dihubungkan oleh variabel kepuasan pelanggan. Kualitas layanan juga memiliki andil sebagai variabel mediasi sebagian atau parsial dimana tanpa adanya pemediasi kualitas layanan terhadap loyalitas pelanggan sudah memengaruhi secara positif dan signifikan.

Pengaruh total dalam penelitian ini menunjukkan bahwa jumlah pengaruh dari hubungan langsung dan tidak langsung antar variabel, dimana pengaruh total merupakan jumlah pengaruh langsung ditambah pengaruh tidak langsung. Tabel 5 menunjukkan variabel kepuasan pelanggan bersaing sebagai variabel perantara antara variabel kualitas layanan dengan loyalitas pelanggan sebesar 0,348 , sehingga pengaruh total antara variabel kualitas layanan dengan loyalitas pelanggan sebesar 0,771 dan sisanya dijelaskan oleh variabel lain.

Uji sobel dirumuskan dengan persamaan berikut dan dapat dihitung dengan menggunakan aplikasi Microsoft Excel 2010. Bila nilai kalkulasi Z lebih besar dari 1,96 (dengan tingkat kepercayaan 95 persen), maka variabel mediator dinilai secara signifikan memediasi hubungan antara variabel endogen dan variabel eksogen. 
Keterangan :

$$
\begin{aligned}
& \mathrm{S}_{\mathrm{ab}}=\text { besarnya standar error tidak langsung } \\
& \mathrm{S}_{\mathrm{a}}=0,044 \\
& \mathrm{~S}_{\mathrm{b}}=0,141 \\
& \mathrm{a}=0,897 \\
& \mathrm{~b}=0,388 \\
& \mathrm{~S}_{\mathrm{ab}}=\sqrt{\mathrm{b}^{2} \mathrm{Sa}^{2}+\mathrm{a}^{2} \mathrm{Sb}^{2}+\mathrm{Sa}^{2} \mathrm{Sb}^{2}} \\
& \mathrm{~S}_{\mathrm{ab}}=\sqrt{\left(0,388^{2}\right)\left(0,044^{2}\right)+\left(0,897^{2}\right)\left(0,141^{2}\right)+\left(0,044^{2}\right)\left(0,191^{2}\right)} \\
& \mathrm{S}_{\mathrm{ab}}=\sqrt{0,0002+0,0159+0,00003} \\
& \mathrm{~S}_{\mathrm{ab}}=\sqrt{0,0161} \\
& \mathrm{~S}_{\mathrm{ab}}=0,1270 \\
& \mathrm{Z}=\frac{a b}{S a 2 b} \\
& =0,3480 / 0.1270 \\
& =2,7401
\end{aligned}
$$

Berdasarkan hasil Uji Sobel dalam penelitian ini menunjukkan bahwa hasil tabulasi $\mathrm{Z}=2,7401>1,96$ dengan tingkat signifikansi $0,000<0,05$ yang berarti variabel mediasi yakni kepuasan pelanggan dinilai secara signifikansi mampu memediasi pengaruh kualitas layanan terhadap maskapai penerbangan AirAsia.

Berdasarkan hasil olahan data diperoleh nilai koefisien beta sebesar 0,897 dengan tingkat signifikansi sebesar 0,000 (kurang dari 0,05) dimana hal ini berarti $\mathrm{H}_{0}$ ditolah dan $\mathrm{H}_{1}$ diterima, yang mengindikasikan bahwa kulitas layanan 
berpengaruh positif dan signifikan terhadap kepuasan. Hasil ini berarti bahwa semakin tinggi kredibilitas dari kualitas layanan maka akan mengingkatkan kepuasan pelanggan pada maskapai penerbangan AirAsia. Hasil penelitian ini sesuai dengan penelitian-penelitian yang dilakukan sebelumnya oleh (Djanas, 2016), (Djawoto, 2017), (Lee, 2013), (Kaura, 2015), (Adil, 2013) yang menunjukkan hasil yang positif dan signifikan anatara pengaruh kualitas layanan terhadap kepuasan pelanggan pada jasa maskapai penerbangan AirAsia.

Berdasarkan hasil olahan data diperoleh nilai koefisien beta positif sebesar 0,423 dengan tingkat signifikansi sebesar 0,001 (kurang dari 0,05) dimana hal ini berarti $\mathrm{H}_{0}$ ditolak dan $\mathrm{H}_{1}$ diterima, yang mengindikasikan bahwa variabel kualitas layanan secara positif dan signifikan berpenagruh terhadap variabel loyalitas pelanggan. Hasil ini berarti semakin baik kualitas layanan yang diberikan maka akan semakin meningkat loyalitas pelanggan pada jasa masakapai penerbangan AirAsia. Hasil penelitian ini sesuai dengan penelitian-penelitan yang dilakukan sebelumnya oleh (Arab, 2012), (Mosahab, 2010), (Lee, 2013), (Mardikawati \& Farida, 2013), (Permana \& Nurcahya, 2014) yang menunjukkan hasil yang positif dan signifikan antara pengaruh kualitas layanan terhadap loyalitas pelanggan.

Berdasarkan hasil olahan data diperoleh nilai koefisien beta positif sebesar 0,388 dengan tingkat signifikansi sebesar 0,002 (kurang dari 0,05) dimana hal ini berarti $\mathrm{H}_{0}$ ditolak dan $\mathrm{H}_{1}$ diterima. Hal ini mengindikasikan bahwa variabel kepuasan pelanggan secara positif dan sgnifikan berpengaruh terhadap variabel loyalitas pelanggan. Hasil ini berarti bahwa semakin positif kepuasan pelanggan terhadap suatu jasa/produk maka akan semakin tinggi pula loyalitas pelanggan 
untuk menggunakan jasa pada maskapai penerbangan AirAsia. Hasil ini sesuai dengan penelitian-penelitian yang dilakukan sebelumnya oleh (Yulisetiarini, 2016), (Ishak, 2011), (Jahanshahi, 2011), (Asgharian, 2012), (Lee, 2013), (Raharjo, 2013), (Sandada \& Matibiri, 2015) yang menunjukkan hasil yang positif dan signifikan antara pengaruh kepuasan pelanggan terhadap loyalitas pelanggan.

Uji Sobel menunjukkan bahwa kepuasan pelanggan secara signifikan memediasi pengaruh kualitas layanan terhadap loyalitas pelanggan dengan hasil $\mathrm{Z}$ sebesar 2,7401 > 1,96 dengan demikian pada hipotesis keempat penelitian ini diterima. Hasil ini memberikan arti bahwa variabel mediasi yaitu kepuasan pelanggan memberikan pengaruh pada hubungan variabel kualitas layanan terhadap loyalitas pelanggan. Melihat dari hasil olahan data yang tertera pada tabel 4.14 menujukkan bahwa nilai pengaruh secara tidak langsung $(0,348)$, hasil ini menunjukkan bahwa pengaruh tidak langsung terhadap kualitas layanan dengan loyalitas pelanggan akan meningkat apabila pengaruh tersebut dihubungkan dengan kepuasan pelanggan, kemudian setelah adanya kepuasan sebagai variabel mediasi nilai pada kualitas layanan terhadap loyalitas pelanggan meningkat menjadi sebesar $(0,771)$. Hasil olahan data memberikan arti bahwa $\mathrm{H}_{4}$ yang menyatakan kepuasan pelanggan dapat memediasi pengaruh kualitas layanan terhadap loyalitas pelangg an pada konsumen yang menggunakan jasa penerbangan AirAsia dapat diterima. Hasil ini berarti baik bagi AirAsia dalam meningkatkan layanan untuk mendapatkan keloyalan dan kepuasan dari konsumen. Hasil ini sesuai dengan penelitian-penelitian sebelumnya yang dilakukan oleh (Starini, 2013), (Malik, 2012), (Aditya \& Kusumadewi, 2017), (Irnandha, 2017) yang menunjukan hasil 
Anak Agung Ayu Ratna Maheswari dan Ni Made Asti Aksari, Peran Kepuasan Pelanggan...

bahwa kepuasan pelanggan dapat memediasi pegaruh kualitas layanan terhadap loyalitas pelanggan pada jasa maskapai penerbangan AirAsia.

Penelitian ini memberikan beberapa implikasi, pertama, kualitas layanan dapat mempengaruhi loyalitas pelanggan secara langsung maupun melalui kepuasan pelanggan. Hal ini menunjukkan bahwa pelayanan yang diberikan oleh AirAsia harus dioptimalkan, karena semakin optimal kegiatan pelayanan yang dilakukan oleh AirAsia maka kepuasan pelanggan akan meningkat. Hal ini membuat AirAsia lebih dikenal dan melekat dalam benak konsumen.

Implikasi kedua adalah kepuasan pelanggan menjadi faktor penting dalam mewujudkan loyalitas pelanggan. Implikasi ketiga adalah kualitas layanan, kepuasan pelanggan, dan loyalitas pelanggan berkaitan satu dengan yang lainnya, sehingga pihak AirAsia diharapkan dapat menentukan layanan yang sesuai dengan kebutuhan masyarakat, agar masyarakat loyal terhadap AirAsia dan AirAsia dapat mendominasi pasar pada jasa penerbangan.

\section{SIMPULAN DAN SARAN}

Hasil dari penelitian ini menunjukkan bahwa kualitas layanan berpengaruh positif dan signifikan terhadap kepuasan pelanggan, artinya apabila terjadi peruba han pada kualitas layanan maka kepuasan pelanggan juga akan mengalami perubahan. Pengaruh hubungan ini menunjukkan adanya nilai positif, artinya semakin tinggi kualitas layanan maka semakin tinggi pula kepuasan pelanggan maskapai penerbangan AirAsia, dan begitu pula sebaliknya. Kualitas layanan berpengaruh positif dan signifikan terhadap loyalitas pelanggan, hal ini 
menunjukkan bahwa kualitas layanan yang diberikan kepada konsumen dapat mempengaruhi loyalitas pelanggan terhadap maskapai penerbangan AirAsia. Kepuasan pelanggan berpengaruh positif dan signifikan terhadap loyalitas pelanggan, hal ini menunjukkan bahwa kepuasan pelanggan pada maskapai penerbangan AirAsia dapat mempengaruhi loyalitas pelanggan, artinya apabila jasa penerbangan AirAsia mampu menciptakan kepuasan pelanggan maka akan tercipta loyalitas pelanggan yang diinginkan. Kepuasan pelanggan mampu memediasi pengaruh kualitas layanan teradap loyalitas pelanggan, dengan kata lain kepuasan pelanggan dapat memperkuat kualitas layanan teradap loyalitas pelanggan pada jasa penerbangan AirAsia.

Berdasarkan hasil penelitian ini, untuk dapat meningkatkan kualitas layanan perusahaan, saran yang dapat diberikan pada pihak AirAsia adalah untuk memperhatikan ketepatan waktu keberangkatan pesawat agar sesuai dengan jadwal keberangkatan pesawat. Dengan tepatnya waktu keberangkatan pesawat AirAsia, pelanggan akan merasa puas sehingga loyalitas pelanggan terhadap AirAsia juga akan meningkat. Penelitian selanjutnya dapat menguji model dalam penelitian ini dengan mengujinya pada wilayah lain atau yang lebih besar, serta mengembangkan model penelitian dengan menguji pengaruh variabel lain seperti harga, citra merek, dan niat beli ulang dalam kaitannya dengan loyalitas pelanggan, kualitas layanan, dan kepuasan pelanggan.

\section{REFERENSI}

Adil, M. (2013). The Relationship Between Service Quality and Customer Satisfaction in India's Rural Banking Sector: An Item Analysis and FactorSpecific Approach. The Lahore Journal of Business, 1(2), 43-63. http://www.lahoreschoolofeconomics.edu.pk/businessjournals/V1 issue2/03 Adil.pdf 
Aditya, M. P., \& Kusumadewi, N. M. W. (2017). Peran Kepuasan Pelanggan dalam Memediasi Pengaruh Kualitas Pelayanan terhadap Loyalitas Pelanggan. EJurnal Manajemen Unud, 6(9), 5061-5087.

Afifah, R. N. (2014). Analisis Pengaruh Kualitas Produk, Kualitas Pelayanan Dan Promosi Terhadap Kepuasan Konsumen Untuk Meningkatkan Loyalitas Pelanggan. Universitas Diponegoro.

Airasia. (2012). Profil Perusahaan. Retrieved from http://www.airasia.com/id/id/about-us/corporate-profile.page

Arab, M., Zarei, E., Daneshkohan, A., Pouragha, B., \& Marzban, S. (2012). An Empirical Study of the Impact of Service Quality on Patient Satisfaction in Private Hospitals, Iran. A Study of Private Hospitals in Tehran, Iran. Iranian J Publ Health, 41(9), 71-77. https://doi.org/10.5539/gjhs.v7n1p1

Artha, I. N. A. G. J. (2019). Peran Kepuasan Pelanggan Dalam Memediasi Pengaruh Kualitas Layanan Terhadap Loyalitas Pelanggan. E-Jurnal Manajemen Unud, 8(1), 7458-7485.

Asgharian, R., \& Salehi, M. (2012). Green product quality, green customer satisfaction, and green customer loyalty. International Journal of Research in Management \& Technology, 2(5), 499-503.

Djanas, A. (2016). Kualitas Pelayanan dan Citra Perusahaan terhadap Kepuasan Serta dampaknya terhadap Loyalitas Wisatawan. JSM (Jurnal Sains Manajemen) Program, V(2), 184-192.

Fikri, S., Wiyani, W., \& Suwandaru, A. (2016). Pengaruh Kualitas Pelayanan Terhadap Kepuasan Dan Loyalitas Mahasiswa (Studi pada Mahasiswa Strata I Fakultas Ilmu Sosial dan Ilmu PolitikUniversitas Merdeka Malang). Jurnal Bisnis Dan Manajemen, 3(1), 120-134.

Hafeez, S., \& Muhammad, B. (2012). The impact of service quality , customer satisfaction and loyalty programs on customer's loyalty. International Journal of Busines and Social Science, 3(16), 200-209. http://www.ijbssnet.com/journals/Vol_3_No_16_Special_Issue_August_201 2/21.pdf

Interaktif, T. (2009). Penerbangan Horor AirAsia. Retrieved from http://blog.tempointeraktif.com/ekonomi-bisnis/557/

Irnandha, A. (2017). Pengaruh Kualitas Layanan Terhadap Loyalitas Pelanggan Yang Dimediasi Oleh Kepuasan Pelanggan Jasa Pengiriman Jalur Darat (Studi Kasus Kepuasan Pelanggan Jne Cabang Hijrah Sagan Yogyakarta). Jurnal Manajemen Bisnis Indonesia (JMBI), 6(6), 660-669.

Ishak, A. (2011). Pengaruh Kepuasan Dan Kepercayaan Konsumen Terhadap Loyalitas: Studi Tentang Peran Mediasi Switching Costs. Jurnal Siasat Bisnis, 
15(1), 55-56.

Jahanshahi, A. A., \& Gashti, M. A. H. (2011). Study the Effects of Customer Service and Product Quality on Customer Satisfaction and Loyalty. International Journal of Humanities and Social Science, 1(7), 253. Retrieved from www.ijhssnet.com

Kaura, V., Durga Prasad, C. S., \& Sharma, S. (2015). Service Quality, Service Convenience, Price and Fairness, Customer Loyalty, and The Mediating Role of Customer Satisfaction. International Journal of Bank Marketing, 33(4), 404-422. https://doi.org/10.1108/IJBM-04-2014-0048

Lee, H. S. (2013). Major Moderators Influencing The Relationships Of Service Quality, Customer Satisfaction And Customer Loyalty. Asian Social Science, 9(2), 1-11. https://doi.org/10.5539/ass.v9n2p1

Maimunah, D. L., \& Djawoto. (2017). Pengaruh Kualitas Pelayanan Harga dan Citra Perusahaan terhadap Kepuasan Pelanggan. Jurnal Ilmu Dan Riset Manajemen, 6(12), 1-18.

Malik, P. D. M. E., Ghafoor, M. M., \& Iqbal, H. K. (2012). Impact Of Brand Image, Service Quality And Price On Customer Satisfaction In Pakistan Telecommunication Sector. International Journal of Business and Social Science, 3(23), 123-129. Retrieved from http://ijbssnet.com/journals/Vol_3_No_23_December_2012/13.pdf

Mardikawati, W., \& Farida, N. (2013). Loyalitas Pelanggan , Melalui Kepuasan Pelanggan Pada Bus Efisiensi ( Studi PO Efisiensi Jurusan YogyakartaCilacap ). Jurnal Administrasi Bisnis, 2(1), 64-75.

Minh, N. V., \& Huu, N. H. (2016). The Relationship between Service Quality, Customer Satisfaction and Customer Loyalty: An Investigation in Vietnamese Retail Banking Sector. Journal of Competitiveness, 8(2), 103-116. https://doi.org/10.7441/joc.2016.02.08

Mosahab, R., Mahamad, O., \& Ramayah, T. (2010). Service Quality, Customer Satisfaction and Loyalty: a Test of Mediation. International Business Research, 3(4), 1-12. https://doi.org/10.5539/ibr.v3n4p72

Nissalke. Thomas, E. (2009). The Transportation System In The 21th Century. Oxford, United Kingdom: Eolss Publishers CO. Ltd.

Pamungkas, G., \& Barata, D. D. (2016). Pengaruh Kualitas Pelayanan Terhadap Kepuasan Pelanggan Serta Dampaknya Terhadap Loyalitas Pelanggan Pada SPBU 34.151.37. Jurnal Bisnis Dan Komunikasi, 3(2), 42-48.

Permana, I. M. A. J., \& Nurcahya, I. K. (2014). Pengaruh Kualitas Pelayanan Terhadap Kepuasan Dan Loyalitas Nasabah Pada LPD Desa Adat Kedonganan. E-Jurnal Manajemen Unud, 3(7), 1830-1849. 
Anak Agung Ayu Ratna Maheswari dan Ni Made Asti Aksari, Peran Kepuasan Pelanggan...

Raharjo, A. (2013). Pengaruh Kualitas Produk Terhadap Loyalitas Konsumen Yang Dimediasi Oleh Kepuasan Konsumen Pengguna Kartu "As." Jurnal Manajemen, 9(1), 30-44. https://doi.org/10.4135/9781412963947.n337

Sabir, R. I., \& Irfan, M. (2013). The Impact of Service Quality, Customer Satisfaction and Loyalty Programs on Customer's Loyalty: Evidence from Banking Sector of Pakistan. Journal of Asian Business Strategy, 3(11), 306314.

Sandada, M., \& Matibiri, B. (2015). The Mediating Influence Of Passenger Satisfaction On The Relationship Between Passenger Loyalty Programmes And Passenger Loyalty. Studia Universitatis Babeș-Bolyai Oeconomica, 60(3), 55-68.

Sandy. (2016). Perancangan Strategi Art Directing Dalam Produksi Kampanye Iklan Perusahaan "SafetyLink (Safety Flight With Citilink). Universitas Mercu Buana.

Sauqi, A., \& Handriyono. (2015). Uji Pengaruh Kualitas Layanan Terhadap Kepuasan Dan Loyalitas Pelanggan Tv Berbayar Indovision Cabang Jember. Relasi, 1, 47-67. https://doi.org/10.1017/CBO9781107415324.004

Sobel, M. E. (1982). Asymptotic Confidence Intervals for Indirect Effects in Structural Equation Models. Sociological Methodology, 13, 290-312.

Starini, H. (2013). Pengaruh Kualitas Pelayanan terhadap Loyalitas Konsumen dengan Kepuasan sebagai variabel Mediasi (Studi Pada Toko Basuki Jaya Yogyakarta). Universitas Negeri Yogyakarta.

Statistik, B. P. (2018). Laporan Laju Pertumbuhan Ekonomi Menurut Kabupaten/Kota. Denpasar: BPS Bali.

Sudjarwo, R. A., Arifin, Z., \& Hidayat, K. (2015). Pengaruh Kualitas Pelayanan Terhadap Kepuasan Nasabah Dan Loyalitas Nasabah (Studi pada Nasabah Kredit KPR PT. Bank BTN KCP Tuban). Jurnal Administrasi Bisnis (JAB), 24(1), 1-8.

Surbakti, F. A., \& Djatmiko, T. (2013). Pengaruh Service Quality Dan Price Terhadap Kepuasan Konsumen Airasia Di Bandung. Telekomunikasi, Manajemen Bisnis Bisnis.

Triwijanarko, R. (2018). Gandeng Google Cloud, Air Asia Serius Jadi Maskapai Digital.

Wijayanto, K. (2015). Pengaruh Kualitas Pelayanan Terhadap Kepuasan Dan Loyalitas Nasabah Bank. Ekonomi Manajemen Sumber Daya, 17(1), 38-45.

Yulisetiarini, D. (2016). The Effect of Relationship Marketing towards Costumer Satisfaction and Customer Loyalty on Franchised Retails in East Java. Mediterranean Journal of Social Sciences, 7(1), 333-339. https://doi.org/10.5901/mjss.2016.v7n1p333 